\title{
INVOLVEMENT OF CHROMOSOMES 7, 18 AND X IN MITOMYCIN C-INDUCED MICRONUCLEI
}

\author{
Hovhannisyan $\mathrm{GG}^{1,2 *}$, Mkrtchyan $\mathrm{H}^{1,2}$, Liehr $\mathrm{T}^{2}$, Aroutiounian $\mathrm{R}^{1}$
}

*Corresponding Author: Dr. Galina G. Hovhannisyan, Department of Genetics and Cytology, State University, Biological Faculty, 1 Alex Manoukian Street, Yerevan 375025, Armenia; Tel.: +374-10552354; Fax: +374-10554641; e-mail: hovgalina@list.ru

\begin{abstract}
The involvement of specific chromosomes in the formation of micronuclei (MN) is neither well studied nor understood. We studied the involvement of chromosomes 7, 18 and $\mathrm{X}$ in mitomycin $\mathrm{C}$ (MMC)-induced MN. A total of 1,202 female MN were studied by three-color fluorescence in situ hybridization (FISH) using centromere-specific probes. After a second round of hybridization, using whole chromosome painting probes, $916 \mathrm{MN}$ were evaluated. The frequency of MN containing whole chromosome painting signals for chromosomes $\mathrm{X}$ in 916 male MN was analyzed. Different frequency of involvement of selected chromosomes in MN formation was revealed. Chromosome interphase position, size and inactive (heterochromatinized) state of $\mathrm{X}$ chromosome in females was discussed as possible reasons of their non random involvement in MN formation. There was no clear relationship between chromosome interphase position and size and migration in MN. However, it was shown that $\mathrm{X}$-chromosomal material was over represented in female- and under represented in male-derived MN. We speculated about a preferred inclusion of the inactive female $\mathrm{X}$-chromosome into $\mathrm{MN}$.
\end{abstract}

1 Department of Genetics and Cytology, State University, Biological Faculty, Yerevan, Armenia

2 Institute of Human Genetics and Anthropology, Jena, Germany
Keywords: Chromosomes 7, 18, X; Fluorescence in situ hybridization (FISH); Mitomycin C (MMC); Micronuclei (MN)

\section{INTRODUCTION}

In most eukaryotes including humans, chromosomes are visible and easy to analyze when spread out during metaphase. However, by applying molecular cytogenetics, chromosomes can be visualized, and are arranged so that they do not overlap [1], and keep their shape and general organization in both metaphase and interphase [2-4], but decondensation occurs transversely to the chromosome axis $[2,3]$. The interphase architecture and possible epigenetic consequences of the chromosomal arrangements within human nuclei are a matter of research and discussion $[5,6]$. It has been repeatedly demonstrated that some chromosomes (like \#19) are centrally localized and others are localized at the nuclear periphery (like \#18) [7-11]. These findings have been confirmed for human sperm [11,12].

Micronuclei (MN) are small, extra nuclear bodies that arise in dividing cells from acentric chromosome/chromatid fragments or from whole chromosome/chromatid that lag behind during anaphase and are not included in the daughter nuclei in telophase [13]. The cytokinesis-block micronucleus assay $(\mathrm{CBMN})$ is extensively used for measuring $\mathrm{MN}$ in human lymphocytes, and can be considered as a "cytome" assay that allows genotoxic, cytotoxic and cytostatic events to be captured within one as- 
say [14]. Its key advantages are its ability to detect both clastogenic (causing chromosome disruption and breakage) and aneugenic (inducing aneuploidy) events, and to identify cells that have divided once in culture. Its use in combination with the fluorescence in situ hybridization (FISH) technique using centromeric probes, has been developed to distinguish MN induced by chromosomal loss from those originating from chromosome breakage [15]. How $\mathrm{MN}$ are formed and which DNA is specifically excluded from the main nucleus is not well understood. We have tested the hypothesis that the chromosomal interphase position is directly related to the involvement of a specific chromosome in the formation of MN. We focused on chromosomes 7, 18 and X which are known to be located more peripherally in the nucleus [12] and differed by their size and levels of condensation (for active and inactive $\mathrm{X}$ chromosome).

\section{MATERIALS AND METHODS}

Cytogenetics. Cell suspensions of peripheral blood lymphocytes of one healthy human female and of one healthy male were used. Standard protocols using mitomycin $\mathrm{C}$ (MMC) for $\mathrm{MN}$-induction were applied $[16,17]$. In short, heparinized whole blood was added to RPMI 1640 medium (1:10) containing $10 \%$ fetal bovine serum, $1 \%$ penicillin/ streptomycin and $10 \mu \mathrm{g} / \mathrm{mL}$ phytohemagglutinin. After $22 \mathrm{~h}$ of cultivation, MMC was added at a final concentration $0.1 \mu \mathrm{g} / \mathrm{mL}$. Forty-four hours later, the cultures were supplemented with cytochalasin $\mathrm{B}(3 \mu \mathrm{g} / \mathrm{mL})$ to achieve cytokinesis block. Total incubation time was $72 \mathrm{~h}$ at $37^{\circ} \mathrm{C}$. Hypotonic treatment was performed for 3 min in cold $0.075 \mathrm{M} \mathrm{KCl}$ at $+4^{\circ} \mathrm{C}$. This procedure preserves the cytoplasm, which is required for recognition of cell borders so that $\mathrm{MN}$ can be assigned to their corresponding main nucleus. Fixation was done twice in methanol/ acetic acid (3:1).

Molecular Cytogenetics. Fluorescence in situ hybridization was performed according to standard procedures [18]. One thousand and two hundrend and two female MN were hybridized and evaluated by a three-color-FISH probe set consisting of centromeric probes (cep) for chromosomes 7 (SpectrumRed; Abbott/Vysis, Abbott GmbH \& Co. KG, Wiesbaden, Germany), 18 (SpectrumGreen; Ab-
bott/Vysis) and X (SpectrumOrange; Abbott/Vysis). The positions of MN on the slides were recorded for their further analysis by whole chromosome probes (wcp). In a second round of hybridization, the nuclei/MN were hybridized with the wcp for 7 (SpectrumGreen), 18 (Diethylaminocoumarine) and $\mathrm{X}$ (SpectrumOrange); the three probes were prepared as in [19]. Only 916 of the $1202 \mathrm{MN}$ were evaluated with the wcp probes. The remaining cells could not be relocated due to cell/MN loss on the slides during the second hybridization, since repeated treatment with pepsin and high temperature induces slight destruction of cell material. Nine hundred and sixteen male $\mathrm{MN}$ were evaluated only with the wcp $\mathrm{X}$ probe.

\section{RESULTS AND DISCUSSION}

In situ hybridization with wcp and cep for chromosomes 7, 18 and $\mathrm{X}$ was used to analyze the presence of specific chromosomal material in MN induced in human lymphocytes by MMC. Mitomycin $\mathrm{C}$ is often used as a positive control in studies with $\mathrm{MN}$ tests [20] and is reported to induce breakage mainly in the pericentromeric heterochromatin [21]. The results obtained are shown in Figure 1 and summarized in Table 1. We found that in the female cells a total of $4.16 \% \mathrm{MN}$ contain centromere-specific signals and $8.41 \% \mathrm{MN}$ contain wcp signals from the three selected chromosomes. X-linked material with wcp signals were detected twice as often $(4.25 \%)$ in a MN as that of chromosomes 7 and 18 (2.07\% for both). Also, the representation of centromeric signals for chromosome $\mathrm{X}$ in $\mathrm{MN}(2.16 \%)$ was higher than for chromosomes 18 (1.24\%) and 7 (0.77\%). While the frequency of wcp signals in $\mathrm{MN}$ is the same for both chromosomes 7 and 18, the frequency of MN containing centromere signals for chromosome 18 is 1.7 -times higher than for chromosome 7. We found that only nine of the male MN contained wcp X-positive material, i.e., $0.99 \%$.

Therefore, on the basis of the results obtained in this study, different frequency of involvement of selected chromosomes in MMC-induced MN formation has been demonstrated. It was shown that chromosomes 7, 18 and $\mathrm{X}$ with the analogous peripheral localization in the nucleus [12] were involved in the formation of $\mathrm{MN}$ with different rates. To answer the question if a correlation is to be suggested for $\mathrm{MN}$ 

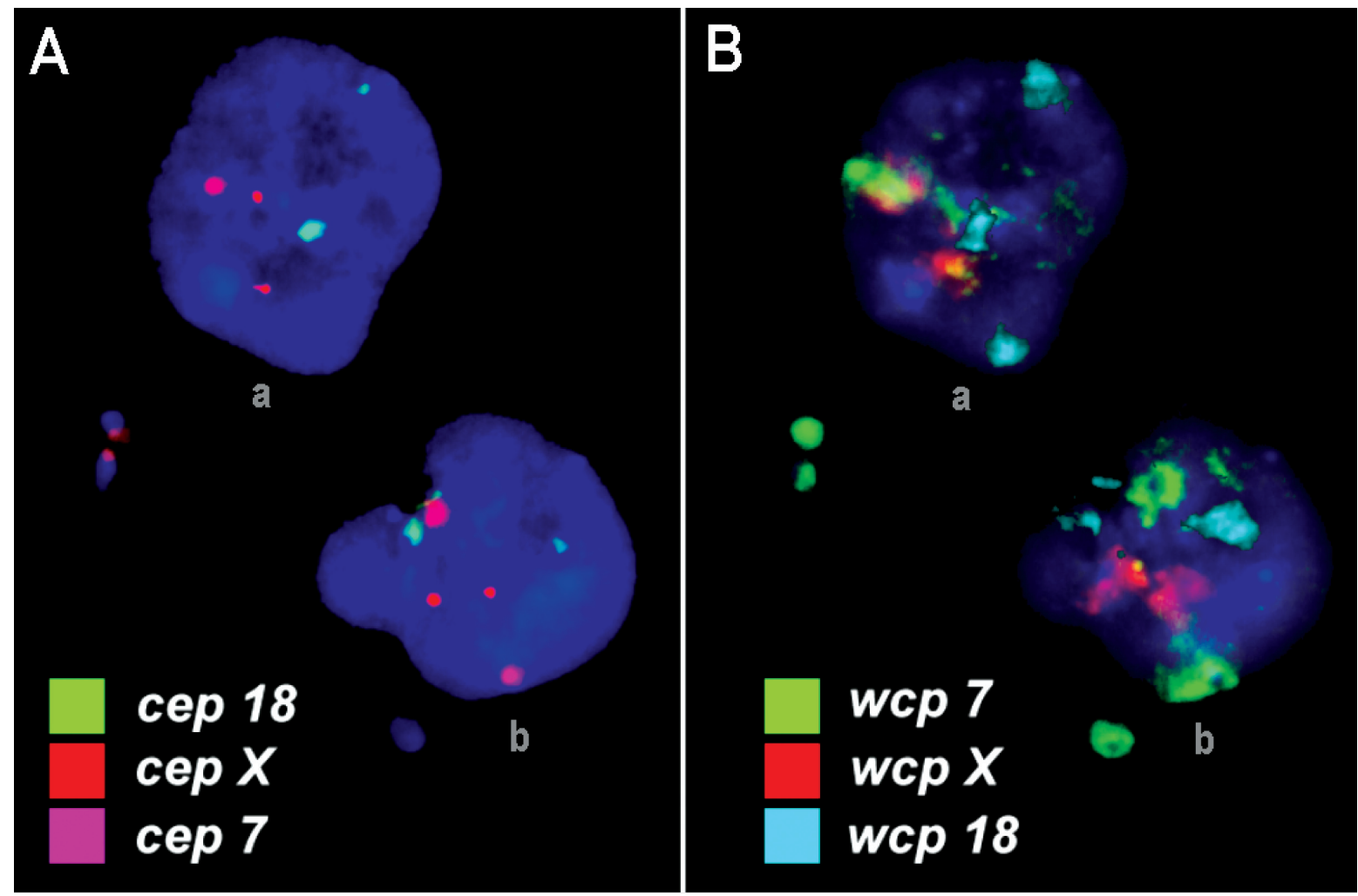

Figure 1. Image of a binucleated cell with three $\mathrm{MN}$ after three-color FISH with cep (A) and wcp (B) for 7, 18 and $\mathrm{X}$ chromosomes. In (A), both MN derived from "nucleus a" contain centromeric material from chromosome 7. In (B), both MN derived from "nucleus a" also contain whole chromosome probe signals from chromosome 7. Micronuclei derived from "nucleus b" did not provide centromeric material, but include wcp from chromosome 7 .

Table 1. Frequencies of microneuclei with positive centromeric and whole chromosome painting signals for chromosomes 7, 18 and $\mathrm{X}$ in human female and male lymphocytes treated with mitomycin-C

\begin{tabular}{|l|c|c|c|}
\hline & $\begin{array}{c}\text { Chromosome } \\
\text { Number }\end{array}$ & $\begin{array}{c}\text { Number of MN With Centromeric } \\
\text { Signals (\%) in 1202 MN Scored }\end{array}$ & $\begin{array}{c}\text { Number of MN With Whole Chromosome } \\
\text { Painting Signals (\%) in 916 MN Scored }\end{array}$ \\
\hline \multirow{3}{*}{ Female Cells } & $\mathrm{X}$ & $26(2.16)$ & $39(4.25)$ \\
& 7 & $9(0.74)$ & $19(2.07)$ \\
& 18 & $50(4.16)$ & $77(8.41)$ \\
\hline Male Cells & $\mathrm{X}$ & n.d. & $9(0.99)$ \\
\hline
\end{tabular}

formation and the chromosomal position within the interphase nucleus further studies are necessary. In case of a direct correlation of chromosome size and participation in $\mathrm{MN}$ formation a distribution, as shown in Figure 2 (red bars), would have to be expected. For chromosomes X (in females) and 18, such a correlation could exist, although we did not observe it for chromosomes 7 and $\mathrm{X}$ (in males).
Thus, chromosome size could be important but not the single factor for chromosome-specific MN formation. The obvious difference between male- and female-derived MN contained wcp X-positive material ( 0.99 versus $4.25 \%)$ has been established. Even though the dosage of the X-chromosome is only half in male, an additional effect seems to drive a more preferred inclusion of (at least) one X- 


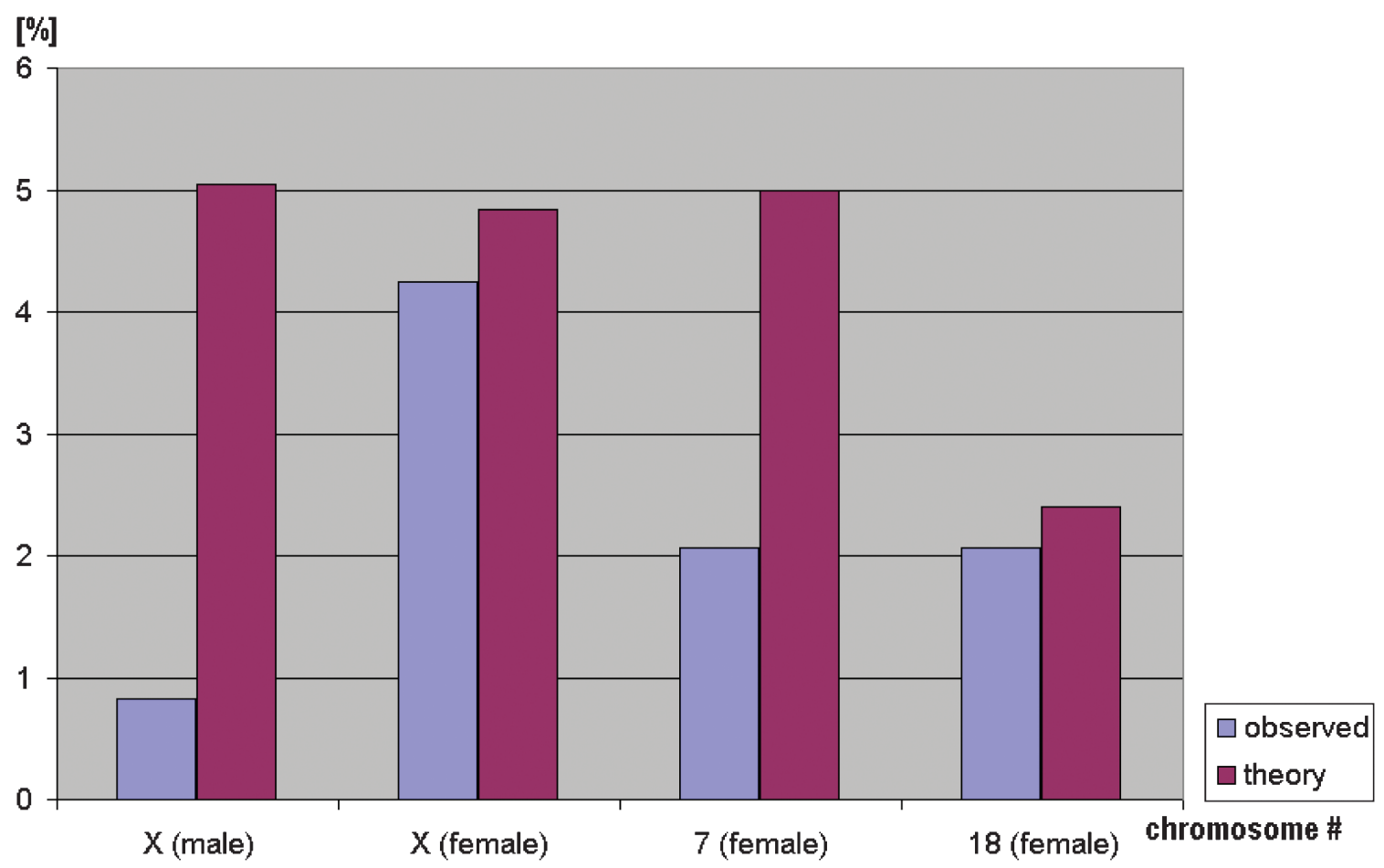

Figure 2. Comparison of the theoretically expected participation of chromosomes 7, 18 and $\mathrm{X}$ in $\mathrm{MN}$ formation (red bars) with the actual observed values (blue bars). The theoretic values were calculated according to the chromosome size and the concept that, the bigger the chromosome the more they should be involved in $\mathrm{MN}$ formation.

chromosome in female. Thus, an effect of increased probability of damage of inactive $X$-chromosome in female has here at least to be discussed (see Figure 2). Finally, MMC-induced MN could involve other chromosomes and/or chromosomal parts than $\mathrm{MN}$ induced by other chemicals. Better knowledge of $\mathrm{MN}$ formation would enable the use of appropriate FISH probes, and improve the efficiency and value of this test [22].

\section{ACKNOWLEDGMENTS}

This study was supported mainly by the DFG (LI 820/13-1) and in part by the Dr. Robert PflegerStiftung, Stiftung Leukämie, Stefan-Morsch-Stiftung, and the DFG (436 ARM 17/11/06, LI 820/151; LI 820/9-1). We are grateful to Dr. T. Lörch and Dr. A. Plesch from MetaSystems (Altlussheim, Germany) for ongoing constructive help.

\section{REFERENCES}

1. Cremer T, Cremer C. Chromosome territories, nuclear architecture and gene regulation in mammalian cells. Nat Rev Genet 2001; 2(4): 292301.

2. Lemke J, Claussen J, Michel S, Chudoba I, Mühlig P, Westermann M, Sperling K, Rubtsov N, Grummt UW, Ullmann P, Kromeyer-Hauschild K, Liehr T, Claussen U. The DNA-based structure of human chromosome 5 in interphase. Am J Hum Genet 2002; 71(5): 1051-1059.

3. Weise A, Starke H, Heller A, Uwe C, Liehr T. Evidence for interphase DNA decondensation transverse to the chromosome axis: a multicolor banding analysis. Int J Mol Med 2002; 9(4): 359361.

4. Iourov IY, Liehr T, Vorsanova SG, Kolotii AD, Yurov YB. Visualization of interphase chro- 
mosomes in postmitotic cells of the human brain by multicolour banding (MCB). Chromosome Res 2006; 14(3): 223-229.

5. Tanabe H, Kupper K, Ishida T, Neusser M, Mizusawa H. Inter- and intra-specific gene-density-correlated radial chromosome territory arrangements are conserved in Old World monkeys. Cytogenet Genome Res 2005; 108(1-3): 255-261.

6. Schneider R, Grosschedl R. Dynamics and interplay of nuclear architecture, genome organization, and gene expression. Genes Dev 2007; 21(23):3027-3043.

7. Croft JA, Bridger JM, Boyle S, Perry P, Teague P, Bickmore WA. Differences in the localization and morphology of chromosomes in the human nucleus. J Cell Biol 1999; 145(6):11191131.

8. Bolzer A, Kreth G, Solovei I, Koehler D, Saracoglu K, Fauth C, Muller S, Eils R, Cremer C, Speicher MR, Cremer T. Three-dimensional maps of all chromosomes in human male fibroblast nuclei and prometaphase rosettes. PLoS Biol 2005; 3(3): e157.

9. Branco MR, Pombo A. Intermingling of chromosome territories in interphase suggests role in translocations and transcription-dependent associations. PLoS Biol 2006; 4(5): e138.

10. Walter J, Joffe B, Bolzer A, Albiez H, Benedetti PA, Muller S, Speicher MR, Cremer T, Cremer M, Solovei I. Towards many colors in FISH on 3D-preserved interphase nuclei. Cytogenet Genome Res 2006; 114(3-4): 367-378.

11. Manvelyan M, Hunstig F, Mrasek K, Bhatt S, Pellestor F, Weise A, L iehr T. Position of chromosomes 18, 19, 21 and 22 in 3D-preserved interphase nuclei of human and gorilla and white hand gibbon. Mol Cytogenet 2008; 1(1): 9.

12. Manvelyan M, Hunstig F, Bhatt S, Mrasek K, Pellestor F, Weise A, Simonyan I, Aroutiounian $\mathrm{R}$, Liehr T. Chromosome distribution in human sperm - a 3D multicolor banding-study. Mol Cytogent 2008; 1(1): 25.
13. Mateuca R, Lombaert N, Aka PV, Decordier I, Kirsch-Volders M. Chromosomal changes: induction, detection methods and applicability in human biomonitoring. Biochimie 2006; 88(11): 15151531.

14. Fenech M. Cytokinesis-block micronucleus assay evolves into a "cytome" assay of chromosomal instability, mitotic dysfunction and cell death. Mutat Res 2006; 600(1-2): 58-66.

15. Schuler M, Rupa DS, Easmond DA. A critical evaluation of centromeric labelling to distinguish micronuclei induced by chromosomal loss and breakage in vitro. Mutat Res 1997; 392(1-2): 81-95.

16. Fenech $M$. The in vitro micronucleus technique. Mutat Res 2000; 455(1-2): 81-95.

17. Rosefort C, Fauth E, Zankl H. Micronuclei induced by aneugens and clastogens in mononucleate and binucleate cells using the cytokinesis block assay. Mutagenesis 2004; 19(4): 277-284.

18. Liehr T, Thoma K, Kammler K, Gehring C, Ekici A, Bathke KD, Grehl H, Rautenstrauss B. Direct preparation of uncultured EDTA-treated or heparinized blood for interphase FISH analysis. Appl Cytogenet 1995; 21(6): 185-188.

19. Liehr T, Claussen U. Current developments in human molecular cytogenetic techniques. Curr Mol Med 2002; 2(3): 283-297.

20. Kirsch-Volders M, Sofuni T, Aardema M, Albertini S, Eastmond D, Fenech M, Ishidate M, Kirchner S, Lorge E, Morita T, Norppa H, Surrallés J, Vanhauwaert A, Wakata A. Report from the in vitro micronucleus assay working group. Mutat Res 2003; 540(2): 153-163.

21. Kusakabe H, Takahashi T, Tanaka N. Chromo- some-type aberrations in chromosome 9 after treatment of human peripheral blood lymphocytes with mitomycin $\mathrm{C}$ at the $\mathrm{G}(0)$ phase. Cytogenet Cell Genet 1999; 85(2): 212-216.

22. Leonard A, Rueff J, Gerber GB, Leonard ED. Usefulness and limits of biological dosimetry based on cytogenetic methods. Radiat Prot Dosimetry 2005 ; 115(1-4): 448-454. 